\title{
Role of fathers in social and emotional development of their adolescents across their working profile
}

Received: 24.01.2017; Revised: 21.03.2017; Accepted: 07.04.2017

See end of the paper for authors' affiliations RITU SINGH

Department of Human Development and Family Study, College of Home Science G.B. Pant University of Agriculture and

Technology, Pantnagar, U.S. NAGAR

(UTTARAKHAND) INDIA

Email : ritu.singh07@gmail.com
ABSTRACT : The present research study was carried out to explore and compare the level of social and emotional maturity of adolescents across occupation of fathers. The sample was comprised of randomly selected 277 students studying in class XI at Pantnagar, Uttarakhand. Social Maturity Scale by Rao (1986), Emotional Maturity Scale by Singh and Bharagava (2006) and a self-designed questionnaire were employed to collect data. The result of the study highlighted the significant influence of fathers' occupation on social and emotional maturity of adolescents. Adolescents of class 1 and class 2 service holders were identified to possess significantly higher level of social and emotional maturity than those of class 3 and class 4 service holders. The findings revealed the importance of father's occupation in one's life as adolescents of higher service classwere found significantly morepersonally, inter-personally and socially adequate; emotionally stable and progressive; socially adjusted and independent than their counterparts. Hence, the study suggests that occupational level of father plays an authoritative role in grooming the maturity of an adolescent.

KEY WORDS: Personal adequacy, Inter-personal adequacy, Emotional progression, Personality integration, Social adequacy, Attachment

- HOW TO CITE THIS PAPER : Pant, Kusha and Singh, Ritu (2017). Role of fathers in social and emotional development of their adolescents across their working profile. Asian J. Home Sci., 12 (1) : 34-41, DOI: 10.15740/HAS/AJHS/12.1/34-41. 